\title{
The potential of leaf extract of Pangium edule Reinw as HIV-1 protease inhibitor: A computational biology approach
}

\author{
Sefren Geiner Tumilaar ${ }^{1}$, Fatimawali Fatimawali ${ }^{1}$, Nurdjannah Jane Niode ${ }^{2}$, Yunus Effendi ${ }^{3}$, Rinaldi Idroes ${ }^{4}$, \\ Ahmad Akroman Adam ${ }^{5}$, Ahmed Rakib ${ }^{6}$, Talha Bin Emran ${ }^{7}$, Trina Ekawati Tallei ${ }^{8^{*}}$ \\ ${ }^{1}$ Pharmacy Study Program, Faculty of Mathematics and Natural Sciences, Sam Ratulangi University, Manado, Indonesia. \\ ${ }^{2}$ Department of Dermatology and Venereology, Faculty of Medicine, Sam Ratulangi University, Manado, Indonesia. \\ ${ }^{3}$ Biology Study Program, Faculty of Science and Technology, Al Azhar University, Jakarta, Indonesia. \\ ${ }^{4}$ Department of Pharmacy, Faculty of Mathematics and Natural Sciences, Syiah Kuala University, Banda Aceh, Indonesia. \\ ${ }^{5}$ Dentistry Study Program, Faculty of Medicine, Sam Ratulangi University, Manado, Indonesia. \\ ${ }^{6}$ Department of Pharmacy, Faculty of Biological Sciences, University of Chittagong, Chittagong, Bangladesh. \\ ${ }^{7}$ Department of Pharmacy, BGC Trust University Bangladesh, Chittagong, Bangladesh. \\ ${ }^{8}$ Department of Biology, Faculty of Mathematics and Natural Sciences, Sam Ratulangi University, Manado North Sulawesi, Indonesia.
}

\begin{tabular}{l}
\hline ARTICLE INFO \\
\hline Received on: $13 / 08 / 2020$ \\
Accepted on:23/11/2020 \\
Available online: $05 / 01 / 2021$
\end{tabular}

\section{Key words:}

Pangium edule, Pangi, HIV, in silico, protease inhibitor.

\begin{abstract}
The leaf of Pangi (Pangium edule) is used as food in North Sulawesi. According to a study conducted in vitro, Pangi leaf extract suppressed the replication of the human immunodeficiency virus (HIV) inside CD4 ${ }^{+}$helper T cells. The current study aimed to determine the compounds extracted from Pangi leaves and investigate the potential of the targeted compounds against human immunodeficiency virus type 1 (HIV-1) protease inhibitors (PIs) using an in silico approach. Dry powder of the Pangi leaves was extracted using n-hexane and then analyzed with gas chromatographymass spectrometer (GC-MS) to obtain information about the compounds contained in Pangi leaves. Each compound's potential ability as HIV-1 PIs were evaluated by using AutoDock Vina and compared with nelfinavir and amprenavir, known as potent HIV PIs. Our present study revealed that at least 53 compounds were detected in the n-hexane extract of Pangi leaf using GC-MS analysis. The docking study revealed that (5.beta.) pregnane-3,20.beta.-diol, 14.alpha., 18. alpha.-[4-methyl-3-oxo-(1-oxa-4-azabutane-1,4-diyl)]-diacetate had the most binding affinity against the HIV-1 PIs. This finding provides a strong indication that this compound might have potential as an HIV-1 PIs. Our in silico study concluded that compound (5.beta.) pregnane-3,20.beta.-diol,14.alpha.,18.alpha.-[4-methyl-3-oxo-(1-oxa-4azabutane-1,4-diyl)]-diacetate in Pangi leaf has the potential to be further developed as an inhibitor of HIV-1 protease. Hence, it presumably serves as a very potent anti-HIV lead compound.
\end{abstract}

\section{INTRODUCTION}

Acquired immunodeficiency syndrome is an asexually transmitted disease caused by the human immunodeficiency virus (HIV). This virus attacks the human immune cells, which causes a decrease in the immune system. This type of virus has two main classifications: human immunodeficiency virus type 1 (HIV-1)

\footnotetext{
"Corresponding Author

Trina Ekawati Tallei, Department of Biology, Faculty of Mathematics and Natural Sciences, Sam Ratulangi University, Manado, Indonesia. E-mail:trina_tallei@unsrat.ac.id
}

and human immunodeficiency virus type 2 (HIV-2). Nevertheless, specifically, HIV-1 is mostly found to spread throughout the world and has a higher infection rate than HIV-2 (Eurtivong et al., 2019; Sillapachaiyaporn and Chuchawankul, 2019; Vijayan et al., 2017). The latest report by the World Health Organization (2020) revealed that the estimated annual number of people infected and living with HIV in 2018 was between 32.700 .000 and 44.000.000, whereas in Indonesia alone in 2018, 550.000-750.000 people are living with HIV infections (World Health Organization, 2020).

This virus, classified as a retrovirus, is capable of infecting $\mathrm{CD}^{+}$(cluster differential four) lymphocytes. $\mathrm{CD}^{+}$lymphocytes play an important role to fight infections in the human body, but 
their value can be reduced due to HIV attacks (Moir et al., 2011) and the mechanism of HIV includes the weakening of the immune system by infecting and destroying $\mathrm{CD} 4^{+}$cells, which ultimately disrupts the functioning of human immunity. HIV attaches to the surface of $\mathrm{CD}^{+}$and other cells to get entries. However, the virus will not enter other cells if only attached to the $\mathrm{CD}^{+}$protein (Marchetti et al., 2013; Naif, 2013). Therefore, another way that a virus needs to gain access into cells is the presence of an HIV-1 essential coreceptor. Two primary chemokine receptors that play a significant role in HIV-1 infection are CCR5 and CXCR4 (or fusion) (Maartens et al., 2014; Simon et al., 2006).

Treatment of HIV infection using a different combination of antiretroviral (ART) drugs involves at least three combinations of drugs (Bhatti et al., 2016). There are five classifications of ART drugs circulating in the community: non-nucleoside reverse transcriptase inhibitors, nucleoside reverse transcriptase inhibitors, protease inhibitors (PIs), HIV integrase strand transfer inhibitors, and inhibitors (CCR5 coreceptor antagonist and fusion inhibitors) (Arts and Hazuda, 2012; Namthabad and Mamidala, 2014). The critical step in the PI action occurs at the final stage of the viral maturation before leaving the host cell (Hughes et al., 2011). In the life cycle, PIs are responsible for producing all the viral enzymes and structural proteins needed to produce mature and virulent virions (Ghosh et al., 2016).

Medicinal plants are often used as sources of active compounds that have the potential to be developed as antimicrobial, antifungal, antibacterial, and antiviral (Calland et al., 2012; Estevam et al., 2015; Hu et al., 2013; Ningsih et al., 2019; Nuraskin et al., 2019, 2020; Pratiwi et al., 2015; Rahmad et al., 2019; Sardi et al., 2013; Tallei et al., 2019a; Tallei et al., 2019b). One of the medicinal plants in which the leaves are used as food for the people of North Sulawesi is Pangi (Pangium edule) (Calland et al., 2012; Hu et al., 2013; Rahmad et al., 2019). The plant is a source of many active compounds with antibacterial (Kasim and David, 2013) and antifungal (Membalik et al., 2018) activities, so it is often used as traditional medicines. According to Mapanawang and Elim (2019), Pangi leaf extract had a high inhibition activity to cease the replication of HIV. A previous study revealed that the Cassia fistula's leaf extract had been used as a potential source for a laxative drug (Sakulpanich and Gritsanapan, 2009). Therefore, this research aimed to investigate in silico using molecular docking approach the potential of the compounds in the Pangi leaf to inhibit HIV-1 protease's activity.

\section{MATERIALS AND METHODS}

\section{Sample collection and preparation}

Pangi leaves were collected from Tempang village, North Sulawesi, Indonesia. The leaves were washed with water, air-dried under the shade at room temperature, and made into powder using a mixer grinder.

\section{Extraction of leaves}

$0.5 \mathrm{~g}$ of powdered leaves was extracted in $1 \mathrm{ml} \mathrm{n}$-hexane solvent for 24 hours. The solution was then centrifuged, and the supernatant was used for subsequent analysis.

\section{Gas chromatography-mass spectrometer (GC-MS) analysis}

The identification of the chemical composition of the n-hexane extract of Pangi leaves was performed using gas chromatography (Thermo Scientific TRACETM 1310), linked with a mass spectrometer (Thermo Scientific ISQ LT Single Quadrupole). A $60 \mathrm{~m}$ HP-5MS Ultra Inert capillary column was used as the stationary phase. This column had a length of $30 \mathrm{~m}, 0.25 \mathrm{~mm}$ inner diameter, and $0.25 \mu \mathrm{m}$ film thickness with a maximum temperature of $325 / 350^{\circ} \mathrm{C}$. Chemical ionization with methane gas $(40 \%, 2.0$ $\mathrm{ml} /$ minutes) was employed in the negative ion mode at a voltage of $70 \mathrm{eV}$. Ultra-high purity helium was used as a carrier gas at a constant flow rate of $1 \mathrm{ml} /$ minutes. $1 \mathrm{ml}$ of sample solution was manually inserted in the splitless mode, with a split ratio of 1:50. Injection and mass transfer line temperature were set at $250^{\circ} \mathrm{C}$. The total running time of the GC-MS was 60 minutes.

\section{Receptor preparation}

The docking analysis used in this study followed the methodologies utilized in Tallei et al. (2020). The three-dimensional (3D) structural information of the macromolecule HIV-1 protease (PDB ID: 3NU3) determined by X-ray crystallography was downloaded from the protein data bank (http://www.rcsb.org/pdb). The downloaded HIV-1 protease file was opened using BIOVIA Discovery Studio Visualizer 2020. The attached water molecules and ligand to the receptor were removed, and the receptor was stored in the .pdb format. Using AutoDock Tools (Morris et al., 2009), HIV-1 protease was modified with the addition of polar hydrogen and then allowed to dock ligands flexibly into the protease's rigid binding pocket, while all of the ligands' torsional bonds were set free. The file was saved in .pdbqt format.

\section{Determination of the active site of the receptor}

The potential of the ligand-binding site (pocket) on the HIV-1 receptor 3D structure was identified using the CASTp web server (http://sts.bioe.uic.edu/castp/). CASTp uses the latest algorithms and computational chemical geometric analysis for the receptor's analytical validation cavities and pockets (Tian et al., 2018).

\section{Ligand preparation}

The structures of identified compounds from Pangi leaves were retrieved from PubChem online server (http://pubchem. ncbi.nlm.nih.gov). The targeted compounds were downloaded and saved in .sdf format. Each ligand molecule was added to the OpenBabel software (O'Boyle et al., 2011) and converted to .pdb format. Using AutoDock Tools (Morris et al., 2009), torque adjustment was made by detecting root and adjusted as desired. The file was saved in .pdbqt format.

\section{Receptor-ligand docking}

The AutoDock Tools (Morris et al., 2009) was used to calculate the ligand binding to HIV protease. A grid spacing of 1 $\AA$ and the grid points in X-, Y-, and Z-axis were set at $30 \times 28 \times$ $26 \AA$, respectively. The determination of this grid box has been dependent on the type of docking used. The three-dimensional map is only made as wide as the area to be docked (targeted docking). The grid center coordinates were placed at X: 17.547, Y: 22.310, Z: 970. AutoDock Vina (Trott and Olson, 2009) was used to perform molecular docking. Vina configuration was typed in notepad and saved as "conf.txt." The Vina program was run through a command prompt directed to the folder to be docked using the formula vina-config conf.txt-log log.txt. The results of the docking calculations were obtained in the notepad file format. 


\section{Analysis and visualization}

The docking conformation of the ligands and receptors was determined by selecting the pose which have the highest affinity (most negative Gibbs free energy). The results from each affinity value of the conformation were obtained in the .pdbqt format. The visualization of 3D and two-dimensional (2D) structures from the docking calculations was carried out using BIOVIA Discovery Studio Visualizer 2020. Using this program, the .pdbqt containing the highest affinity score was opened. The interaction of the receptor's amino acid with the ligand in 3D and $2 \mathrm{D}$ was saved as image files.

\section{Lipinski's rule of five (Ro5) determination}

Lipinski's Ro5 components consists of H-bond donor, H-bond acceptor, molecular weight, and an octanol-water partition coefficient $(\log \mathrm{P})$. The pharmacokinetic properties of the compounds were predicted using SCFBIO prediction (http://www. scfbio-iitd.res.in/software/drugdesign/lipinski.jsp).

\section{RESULTS AND DISCUSSIONS}

The n-hexane solvent extracted 53 predicted nonpolar compounds that were detected using GC-MS (Fig. 1). GC-MS is beneficial because it has a reasonably complete function. GC can separate semivolatile and volatile compounds with an excellent resolution; however, it cannot identify them. MS can provide detailed structural information for most compounds so that they can be identified precisely but cannot immediately separate them (Hussain and Maqbool, 2014). However, GC-MS only predicts structure because not all molecules undergo derivatization only once or receive derivatization (Barding et al., 2013). At least, there are 53 possible different components with different similarity index. Some bioactive compounds possess antiviral activities (Mapanawang and Elim, 2019).

The compounds extracted from Pangi are presented in Table 1. Lipinski's Ro5 of each compound and the docking analysis results of all compounds against HIV-1 protease (PDB ID: 3 NU3) are shown in Table 2. All compounds did not violate the
Ro5 criteria. Amprenavir and nelfinavir, which are antiretroviral drugs used in treating the HIV, were used as positive controls.

The active site of the protease HIV-1 receptor was identified using the CASTp web server. The active site was depicted in area 441,854 by volume of 306,180 . A total of 35 amino acid residues on the active site included Arg-A:8, Leu-A:23, Asp-A:25, Gly-A:27, Ala-A:28, Asp-A:29, Asp-A:30, Val-A:32, Lys-A:45, Ile-A:47, Gly-A:48, Gly-A:49, Ile-A:50, Leu-A:76, Thr-A:80, Pro-A:81, Val-A:82, Ile-A:84, Arg-B:108, Leu-B:123, Asp-B:125, Gly-B:127, Ala-B:128, Asp-B:129, Asp-B:130, Val-B:132, Ile-B:147, Gly-B:148, Gly-B:149, Ile-B:150, Gly-B:152, Phe-B:153, Pro-B:181, Val-B:182, and Ile-B:184. The amino acid residues identified by the CASTp web server generated the results as the involvement of the amino acid residues in the native ligandreceptor interactions. This result shows that the ligand's binding site is right on the active site of the receptor. The accuracy of the ligands to bind to the receptor is seen from the amino acid residues that interact in the binding of the ligands and receptors (Rakib et al., 2020). Figure 2 shows the interacting amino acid residues of HIV-1 protease with the native ligand \{3-[(4-aminobenzenesulfonyl)-isobutyl-amino]-1-benzyl-2-hydroxy-propyl \}carbamic acid tetrahydro-furan-3-Y1 ester (native ligand) in 2D (A) and 3D (B) configurations.

Figures 3 and 4 show the docking analysis results displaying the interacting amino acid residues of HIV-1 protease with two ligand molecules served as positive controls and the selected top six ligands that had the best binding affinity among the compounds tested. The bonds between the positive control ligand amprenavir and tested ligands phthalic acid, butyl undecyl ester, bis(3,5,5-trimethylhexyl) phthalate, and octadecane, 3-ethyl5-(2-ethylbutyl) with the receptors showed that all of the binding amino acid residues exactly act on the active site of the receptor. However, control ligands amprenavir and other tested ligands (5.beta.) pregnane-3,20.beta.-diol, 14.alpha., 1 8.alpha.-[4-methyl3-oxo-(1-oxa-4-azabutane-1,4-diyl)]-diacetate, ethyl cholate and psi.,.psi.-carotene, 1,1',2,2'-tetrahydro-1,1'-dimethoxy had one amino acid residue that is not attached to the active site.

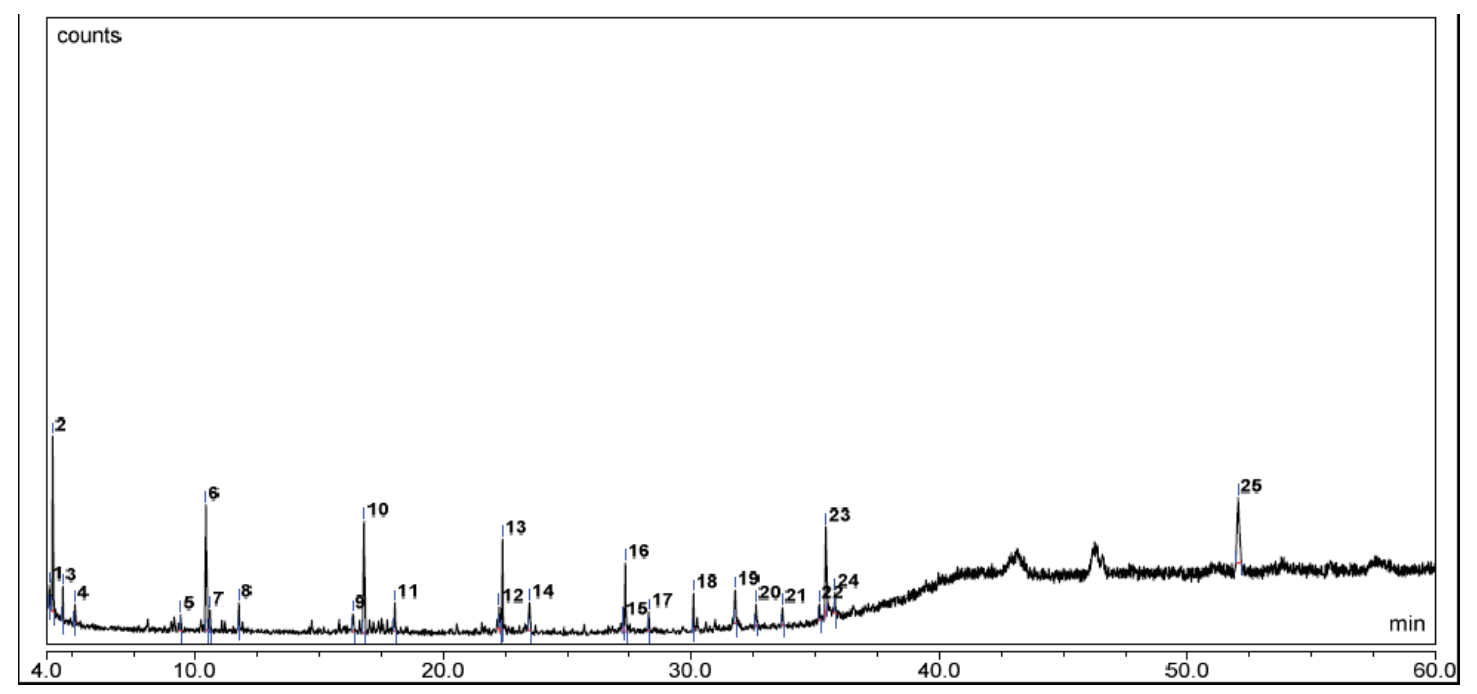

Figure 1. GC-MS chromatogram of n-hexane extract of the leaf of $P$. edule. 
Table 1. Compounds identified using GC-MS analysis from the n-hexane Pangi leaf extract.

\begin{tabular}{|c|c|c|c|c|c|}
\hline Peak & RT & Compound name\#Hit1 & Compound name\#Hit2 & Compound name \#Hit3 & $\begin{array}{l}\text { Ret. area } \\
(\%)\end{array}$ \\
\hline 1 & 4.1 & Hydroxylamine, O-(2-methylpropyl)- & Octadecane, 6-methyl- & Nonane, 4-ethyl-5-methyl- & 1.44 \\
\hline 2 & 4.24 & Hexane, 2,4-dimethyl- & Octane & Heptane, 2,4-dimethyl- & 9.68 \\
\hline 3 & 4.64 & Tridecane, 3-methylene- & 3-Trifluoroacetoxydodecane & 1-Octyn-3-ol & 1.89 \\
\hline 4 & 5.13 & Decane & Hexane, 2,3,4-trimethyl & Octadecane, 6-methyl- & 1.13 \\
\hline 5 & 9.4 & 3,6-Octadecadiynoic acid, methyl ester & 2-Nitrohept-2-en-1-ol & 3-(Prop-2-enoyloxy)dodecane & 1.14 \\
\hline 6 & 10.43 & Decane, 2,3,5,8-tetramethyl- & Decane & Undecane & 9.76 \\
\hline 7 & 10.59 & Octane, 4-ethyl- & Octadecane, 6-methyl- & 1-Decene, 4-methyl- & 1.55 \\
\hline 8 & 11.74 & Tridecane & Octadecane, 6-methyl- & Undecane & 1.87 \\
\hline 9 & 16.34 & Hydroxylamine, O-decyl- & 1-Iodo-2-methylnonane & 2,4,6,8-Tetramethyl-1-undecene & 1.48 \\
\hline 10 & 16.79 & Dodecane, 2,6,11-trimethyl- & 1-Iodo-2-methylundecane & Pentadecane & 9.26 \\
\hline 11 & 18.04 & Octadecane, 6-methyl- & Undecane, 4,8-dimethyl- & Decane, 2,3,5,8-tetramethyl & 2.26 \\
\hline 12 & 22.24 & Octadecane, 6-methyl- & 1-Octadecanesulphonyl chloride & 1-Iodo-2-methylnonane & 2.06 \\
\hline 13 & 22.38 & 1-Iodo-2-methylnonane & 1-Iodo-2-methylundecane & Decane, 2,3,5,8-tetramethyl & 7.54 \\
\hline 14 & 23.47 & Octadecane, 6-methyl- & Dodecane, 2-methyl- & $\begin{array}{l}\text { Heptadecane, } \\
\text { 2,6,10,14-tetramethyl- }\end{array}$ & 2.69 \\
\hline 15 & 27.25 & Octadecane, 3-ethyl-5-(2-ethylbutyl)- & Decane, 2,3,5,8-tetramethyl & Octadecane, 6-methyl- & 0.64 \\
\hline 16 & 27.33 & Eicosane, 2-methyl- & 1-Iodo-2-methylundecane & Decane, 2,3,5,8-tetramethyl & 6.27 \\
\hline 17 & 28.28 & Octadecane, 6-methyl- & Octadecane, 3-ethyl-5-(2-ethylbutyl)- & Eicosane, 7-hexyl- & 1.71 \\
\hline 18 & 30.08 & E-7-Tetradecenol & 3-Decen-1-ol, (E)- & 3-Decen-1-ol, (Z)- & 3.33 \\
\hline 19 & 31.77 & Octadecane, 2,6-dimethyl- & Heptadecane, 2,6-dimethyl- & Octadecane, 6-methyl- & 3.08 \\
\hline 20 & 32.6 & Octadecane, 3-ethyl-5-(2-ethylbutyl)- & Phthalic acid, butyl undecyl ester & $\begin{array}{l}\text { Bis-(3,5,5-trimethylhexyl) } \\
\text { phthalate }\end{array}$ & 1.9 \\
\hline 21 & 33.66 & 2-Decen-1-ol & Trans-2-Undecen-1-ol & Octadecane, 1-(ethenyloxy)- & 1.62 \\
\hline 22 & 35.16 & $\begin{array}{l}\text { Cyclopropanedodecanoic acid, 2-octyl-, } \\
\text { methyl ester }\end{array}$ & Stearic acid, 3-(octadecyloxy)propyl ester & $\begin{array}{l}{\left[1,1^{\prime} \text {-Bicyclopropyl]-2-octanoic }\right.} \\
\text { acid, 2'-hexyl-, methyl ester }\end{array}$ & 1.31 \\
\hline 23 & 35.42 & 3,7,11,15-Tetramethyl-2-hexadecen-1-ol & 1-Hexadecen-3-ol, 3,5,11,15-tetramethyl- & Isophytol & 10.53 \\
\hline 24 & 35.79 & Stearic acid, 3-(octadecyloxy)propyl ester & Octadecane, 3-ethyl-5-(2-ethylbutyl)- & $\begin{array}{l}\text { Octadecanoic acid, } \\
\text { 2-(octadecyloxy)ethyl ester }\end{array}$ & 1.82 \\
\hline 25 & 52.04 & $\begin{array}{l}\text { (5.beta.) Pregnane-3,20.beta.-diol, } \\
\text { 14.alpha.,18.alpha.-[4-methyl-3-oxo-(1-oxa- } \\
\text { 4-azabutane-1,4-diyl)]-diacetate }\end{array}$ & Ethyl cholate & $\begin{array}{l}\text { psi.,.psi.-Carotene, } \\
1,1^{\prime}, 2,2^{\prime} \text {-tetrahydro-1,1'- } \\
\text { dimethoxy- }\end{array}$ & 14.06 \\
\hline
\end{tabular}

HIV-1 protease was chosen as a target receptor because its use as a potential target was validated in experiments that showed that mutations in this protein resulted in defective, noninfectious virus (Patick and Potts, 1998). Its use as a promising target for antiviral drug therapy was shown by previous research results (Ghosh et al., 2016; Patick and Potts, 1998; Razzaghi-Asl et al., 2015). Like other retroviruses, HIV-1 protease is related to the cellular aspartyl protease family, including pepsin and renin (Adamson, 2012). Examples of this group of drugs include saquinavir, ritonavir, indinavir, nelfinavir, amprenavir, lopinavir, atazanavir, and fosamprenavir (Badley, 2005). As a corollary, nelfinavir and amprenavir were selected as positive controls in this study.

The ligand molecules with the least binding energy are considered as the compounds of the highest binding affinity (Chella-Perumal et al., 2014). The compound that has a higher binding affinity more than the comparative ligand (amprenavir and nelfinavir) is (5.beta.) pregnane-3,20.beta.-diol, 14.alpha.,18. alpha.-[4-methyl-3-oxo-(1-oxa-4-azabutane-1,4-diyl)]-diacetate. This compound shows a better score of -17.2 and a peak level in the chromatogram graph indicates the maximum number of the compound (14.06\%). It also has H-bonds with the receptor. The three parameters that are usually taken into consideration when calculating the results are bond affinity, H-bond energy, and residual interactions (Ladokun et al., 2018).

Other compounds phthalic acid, butyl undecyl ester, bis(3,5,5-trimethylhexyl) phthalate, .psi.,.psi.-carotene, $1,1^{\prime}, 2,2^{\prime}$-tetrahydro-1,1'-dimethoxy-, ethyl cholate, Octadecane, 3-ethyl-5-(2-ethylbutyl)- showed the binding affinity value such as $-11,-11,-10.9,-10.5$, and $-10.2 \mathrm{kcal} / \mathrm{mol}$, respectively. These values are higher compared to nelfinavir but not with amprenavir. According to Zhang et al. (2008), HIV-1 proteases that belong to the retroviruses class have a protein dimer structure wherein the protein has two single amino acid subunits that form the symmetry of protein dimers. Each ligand will interact with these two amino acid chains. Therefore, each amino acid residue involved in the interaction is characterized by codes A and B.

The results of molecular docking were visualized with the BIOVIA Discovery Studio 2020 program in 3D and 2D. Interactions occur in the form of hydrophobic interactions, hydrogen bonds, and electrostatic interactions. The more hydrogen bonds formed with amino acid residues, the stronger the bond will be, and the energy score will be lower and more stable (Shah and Misra, 2011). Hydrogen bonds are interactions between hydrogen $(\mathrm{H})$ atoms which are covalently bonded to atoms such as flour $(\mathrm{F})$, nitrogen $(\mathrm{N})$, and 
Table 2. Lipinski's Ro5 of HIV-1 protease potential inhibitors and their binding affinity.

\begin{tabular}{|c|c|c|c|c|c|c|c|}
\hline Ligand properties & PubchemID & $\begin{array}{l}\text { Mol. weight } \\
\quad<500\end{array}$ & HBD $<5$ & $\mathrm{HBA}<10$ & $\log p<5$ & Violation & $\begin{array}{l}\text { Binding energy } \\
(\text { kcal } / \mathrm{mol})\end{array}$ \\
\hline Amprenavir & 65016 & - & - & - & - & - & -12.8 \\
\hline Nelfinavir & 64143 & - & - & - & - & - & -10.1 \\
\hline $\begin{array}{l}\text { (5.beta.) Pregnane-3,20.beta.-diol, 14.alpha.,18. } \\
\text { alpha.-[4-methyl-3-oxo-(1-oxa-4-azabutane-1,4-diyl)]- } \\
\text { diacetate }\end{array}$ & 537242 & 489 & 0 & 6 & 5.96 & 1 & -17.2 \\
\hline Phthalic acid, butyl undecyl ester & 6423450 & 376 & 0 & 4 & 5.58 & 1 & -11 \\
\hline Bis(3,5,5-trimethylhexyl) phthalate & 34277 & 418 & 0 & 4 & 6.69 & 1 & -11 \\
\hline $\begin{array}{l}\text {.psi.,.psi.-Carotene, 1,1',2,2'-tetrahydro-1,1'- } \\
\text { dimethoxy- }\end{array}$ & 5366411 & 312 & 5 & 6 & -0.05 & 0 & -10.9 \\
\hline Ethyl Cholate & 6452096 & 436 & 3 & 5 & 3.93 & 0 & -10.5 \\
\hline Octadecane, 3-ethyl-5-(2-ethylbutyl)- & 292285 & 282 & 0 & 0 & 7.76 & 1 & -10.2 \\
\hline Eicosane, 7-hexyl- & 292289 & 366 & 0 & 0 & 8.22 & 1 & -9.8 \\
\hline Stearic acid, 3-(octadecyloxy)propyl ester & 551406 & 312 & 5 & 6 & -0.05 & 0 & -9.7 \\
\hline Octadecanoic acid, 2-(octadecyloxy)ethyl ester & 545632 & 312 & 5 & 6 & -0.05 & 1 & -9.4 \\
\hline 1-Octadecanesulphonyl chloride & 66281 & 352.5 & 0 & 2 & 6.08 & 1 & -9.3 \\
\hline Eicosane, 2-methyl- & 519146 & 296 & 0 & 0 & 6.69 & 1 & -9.1 \\
\hline Heptadecane, 2,6,10,14-tetramethyl- & 29036 & 296 & 0 & 0 & 7.86 & 1 & -8.9 \\
\hline Cyclopropanedodecanoic acid, 2-octyl-, methyl ester & 534597 & 366 & 0 & 2 & 6.77 & 1 & -8.3 \\
\hline Decane, 2,3,5,8-tetramethyl- & 545611 & 198 & 0 & 0 & 5.13 & 1 & -8.3 \\
\hline Dodecane, 2,6,11-trimethyl- & 35768 & 212 & 0 & 0 & 5.66 & 1 & -8.3 \\
\hline Heptadecane, 2,6-dimethyl- & 545603 & 268 & 0 & 0 & 7.37 & 1 & -8.1 \\
\hline 1-Hexadecen-3-ol, 3,5,11,15-tetramethyl- & 551282 & 296 & 1 & 1 & 6.36 & 1 & -7.9 \\
\hline 3-Trifluoroacetoxydodecane & 534402 & 282 & 0 & 2 & 5.01 & 1 & -7.9 \\
\hline Octadecane, 2,6-dimethyl- & 545598 & 282 & 0 & 0 & 7.76 & 1 & -7.9 \\
\hline Tridecane, 3-methylene- & 519705 & 196 & 0 & 0 & 5.48 & 1 & -7.9 \\
\hline Octadecane, 6-methyl- & 93065 & 268 & 0 & 0 & 7.51 & 1 & -7.8 \\
\hline 2,4,6,8-Tetramethyl-1-undecene & 536235 & 210 & 0 & 0 & 5.44 & 1 & -7.8 \\
\hline Octadecane, 1-(ethenyloxy)- & 13585 & 296 & 0 & 1 & 5.48 & 1 & -7.8 \\
\hline 3-(Prop-2-enoyloxy)dodecane & 543279 & 240 & 0 & 2 & 4.63 & 0 & -7.7 \\
\hline 3,6-Octadecadiynoic acid, methyl ester & 536196 & 290 & 0 & 2 & 4.87 & 0 & -7.7 \\
\hline Pentadecane & 12391 & 212 & 0 & 0 & 6.09 & 1 & -7.7 \\
\hline $\begin{array}{l}{\left[1,1^{\prime} \text {-Bicyclopropyl]-2-octanoic acid, 2'-hexyl-, methyl }\right.} \\
\text { ester }\end{array}$ & 552098 & 322 & 0 & 2 & 6.13 & 1 & -7.5 \\
\hline Dodecane, 2-methyl- & 15270 & 184 & 0 & 0 & 5.17 & 1 & -7.5 \\
\hline Undecane, 4,8-dimethyl- & 28454 & 184 & 0 & 0 & 5.02 & 1 & -7.4 \\
\hline Tridecane & 12388 & 184 & 0 & 0 & 5.32 & 1 & -7.3 \\
\hline Nonane, 4-ethyl-5-methyl- & 519249 & 170 & 0 & 0 & 4.64 & 0 & -7.2 \\
\hline Isophytol & 10453 & 296 & 1 & 1 & 6.36 & 1 & -7.1 \\
\hline Undecane & 14257 & 156 & 0 & 0 & 4.54 & 0 & -7 \\
\hline Trans-2-Undecen-1-ol & 5365004 & 170 & 1 & 1 & 3.28 & 0 & -6.9 \\
\hline 1-Decene, 4-methyl- & 518719 & 154 & 0 & 0 & 4.17 & 0 & -6.8 \\
\hline 2-Propyl-1-heptanol & 24847 & 158 & 1 & 1 & 2.97 & 0 & -6.8 \\
\hline 2-Nitrohept-2-en-1-ol & 5362713 & 159 & 1 & 3 & 1.33 & 0 & -6.6 \\
\hline 3-Decen-1-ol, (E)- & 5352493 & 156 & 1 & 1 & 2.89 & 0 & -6.6 \\
\hline 3-Decen-1-ol, (Z)- & 5352846 & 156 & 1 & 1 & 2.89 & 0 & -6.6 \\
\hline Decane & 15600 & 198 & 0 & 0 & 5.13 & 1 & -6.5 \\
\hline Heptane, 2,4-dimethyl- & 16656 & 128 & 0 & 0 & 3.47 & 0 & -6.5 \\
\hline Octane, 4-ethyl- & 85925 & 142 & 0 & 0 & 4 & 0 & -6.4 \\
\hline 1-Octyn-3-ol & 13166 & 126 & 1 & 1 & 1.56 & 0 & -6.3 \\
\hline E-7-Tetradecenol & 5362726 & 212 & 1 & 1 & 4.46 & 0 & -6.3 \\
\hline
\end{tabular}


Table 2. (Continued)

\begin{tabular}{lccccccc}
\hline Hydroxylamine, O-decyl- & 34704 & 173 & 2 & 2 & 3.02 & 0 & -6.3 \\
3,7,11,15-Tetramethyl-2-hexadecen-1-ol & 5366244 & 296 & 1 & 1 & 6.36 & 1 & -6.2 \\
Hexane, 2,3,4-trimethyl & 13533 & 128 & 0 & 0 & 3.32 & 0 & -6.2 \\
1-Iodo-2-methylnonane & 537317 & 269 & 0 & 0 & 4.18 & 0 & -6.1 \\
Hexane, 2,4-dimethyl- & 11511 & 114 & 0 & 0 & 3.09 & 0 & -6.1 \\
Octane & 356 & 114 & 0 & 0 & 3.37 & 0 & -5.9 \\
2-Decen-1-ol & 5364942 & 156 & 1 & 1 & 2.89 & 0 & -5.8 \\
Hydroxylamine, O-(2-methylpropyl)- & 536422 & 89 & 2 & 2 & 0.53 & 0 & -5.2 \\
1-Iodo-2-methylundecane & 545590 & 297 & 0 & 0 & 5.2 & 1 & -4.9 \\
\hline
\end{tabular}

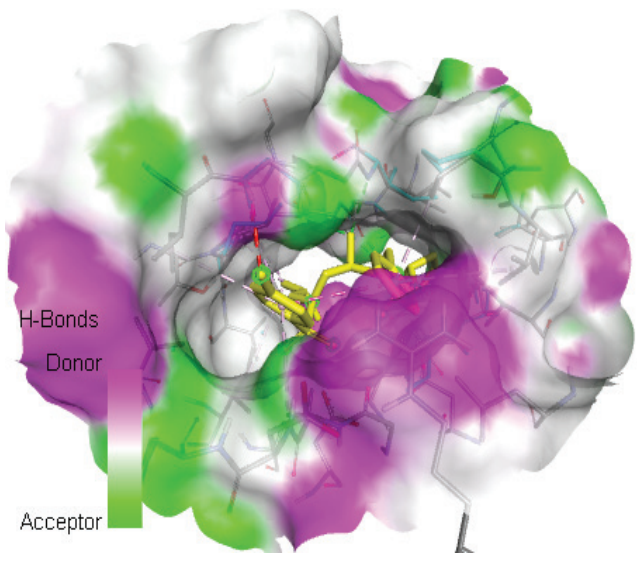

(A)

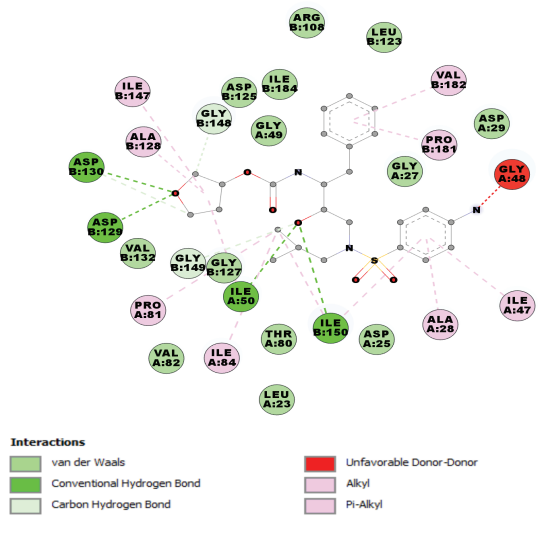

(B)

Figure 2. (A) The 3D configuration of the interacting amino acid residues of HIV-1 protease receptor with the $\{3-[(4$-aminobenzenesulfonyl)-isobutyl-amino]-1-benzyl-2-hydroxy-propyl\}-carbamic acid tetrahydro-furan-3-Yl ester (native ligand) and (B) the $2 \mathrm{D}$ configuration which show the types of contacts formed between receptor and ligand.

oxygen (O) (Glowacki et al., 2013). Figure 4 shows that (5.beta.) pregnane-3, 20.beta.-diol, 14.alpha.,18.alpha.-[4-methyl-3-oxo-(1oxa-4-azabutane-1,4-diyl)]-diacetate has the most hydrogen bonds with amino acids that occur in residues Asp-B:129 and Asp-B:130, so it has the lowest score energy and can also be said to be the most stable ligand among others. Bis(3,5,5-trimethylhexyl) phthalate, psi.,.psi.-carotene, 1,1',2,2'-tetrahydro-1,1'-dimethoxy, and phthalic acid, butyl undecyl ester have only one hydrogen bond that occurs in the Ile-B-150, Gly-B:148, and Gly-B:149 residue, respectively.

Hydrophobic interactions avoid the liquid environment and tend to cluster together in the globular structure of proteins (Lins and Brasseur, 1995). Therefore, the hydrophobic interaction formation can reduce the interaction of amino acid residues with water. Hydrophobic interactions can be in pi-Sigma and alkyl/ pi-Alkyl bonds (Zubair et al., 2020). Six tested ligands have interaction with these bonds. Each of these amino acid residues is a residue of nonpolar amino acids. Nonpolar (hydrophobic) amino acid residues tend to form clusters in the interior of the protein so that they can prevent the protein from coming into contact with water (Arwansyah et al., 2014).

Interactions in each ligand and amino acid residues involve several important residues in the interaction of receptors and ligands. As seen in Figure 4, only (5.beta.) pregnane-3, 20.beta.diol, 14.alpha.,18.alpha.-[4-methyl-3-oxo-(1-oxa-4-azabutane1,4-diyl)]-diacetate and psi.,.psi.-carotene, 1,1',2,2'-tetrahydro- 1,1'-dimethoxy have a salt bridge at residue Asp-A:25 and Asp-B:130. It is because one of the most common forms of salt appears from aspartic acid. The residues Ile-A:50, Gly-B:149, Ile-A:84, Ile-B:184, and Asp-B:130 always appear in every ligandreceptor interaction, both electrostatic interaction and hydrogen bonding. Residue Ile-A:50 and Asp-B:130 are positioned inside the unprotected receptor; therefore, the water molecules make hydrogen bonds with it. It can increase receptor and ligand binding (Perez et al., 2007). According to Brik and Wong (2003), the HIV-1 protease enzyme's active site is located between dimers containing aspartate catalytic residues that contain other supporting subunits. The residue is located at Asp-A: 25, Thr-A: 26, and Gly-A: 27, which also proves that the ligand (5.beta.) pregnane-3, 20.beta.diol, 14.alpha.,18.alpha.-[4-methyl-3-oxo-(1-oxa-4-azabutane-1,4diyl)]-diacetate precisely works on the enzyme's active site.

Al-Fifi et al. (2015) studied chitosan as a ligand added to phenol and hydroxymethylcarbonyl compounds, which were then docked to HIV-1 protease. The ligand has hydrogen bonds with receptors located on the amino acid residues Thr80, Ala28, Gly27, and Asp25. It shows that the amino acid ligand works in 2 areas of the receptor-binding site. Compared with the study of Manikrao et al. (2012), darunavir has hydrogen bonds with receptors located in the amino acid residues Asp-A: 25, Asp-A: 30, Asp-B: 25, Asp-B: 29, and Asp-B: 30. This ligand is one of the synthetic drugs approved by the Food and Drug Association 


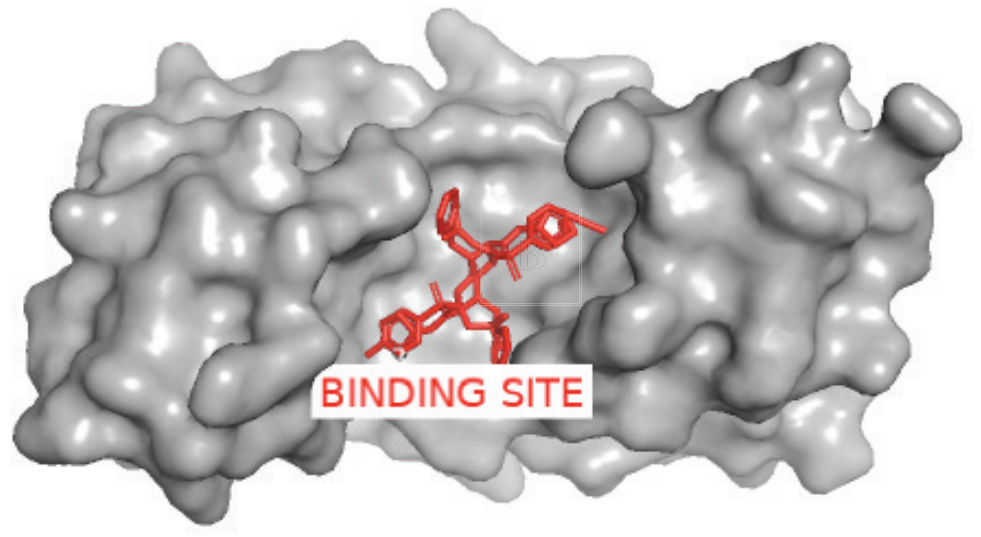

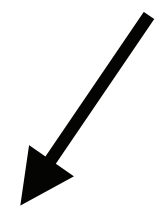

A

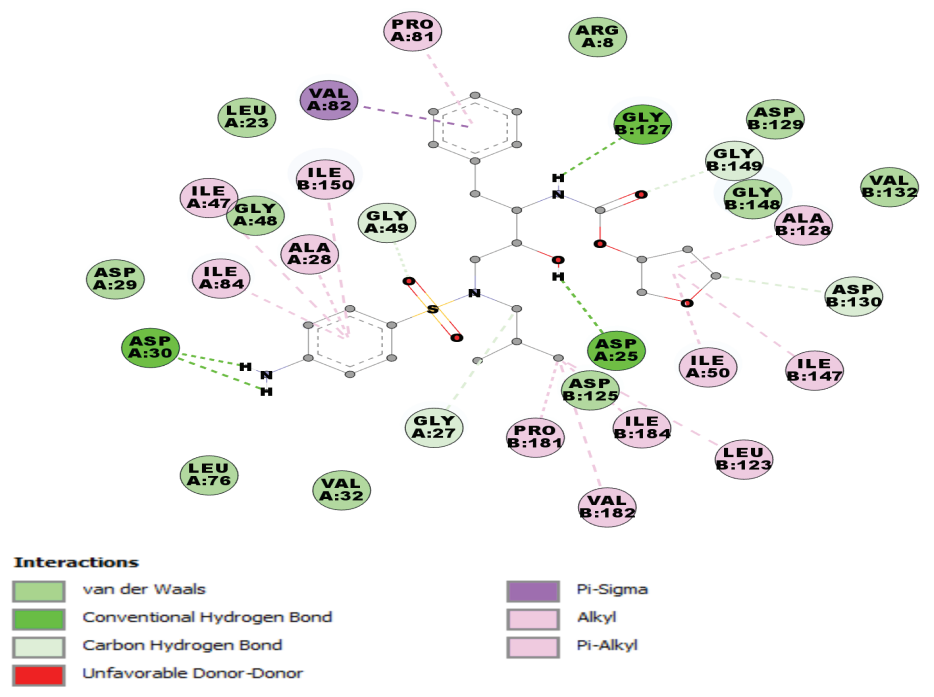

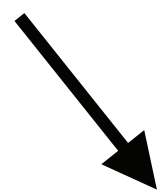

$\mathrm{B}$

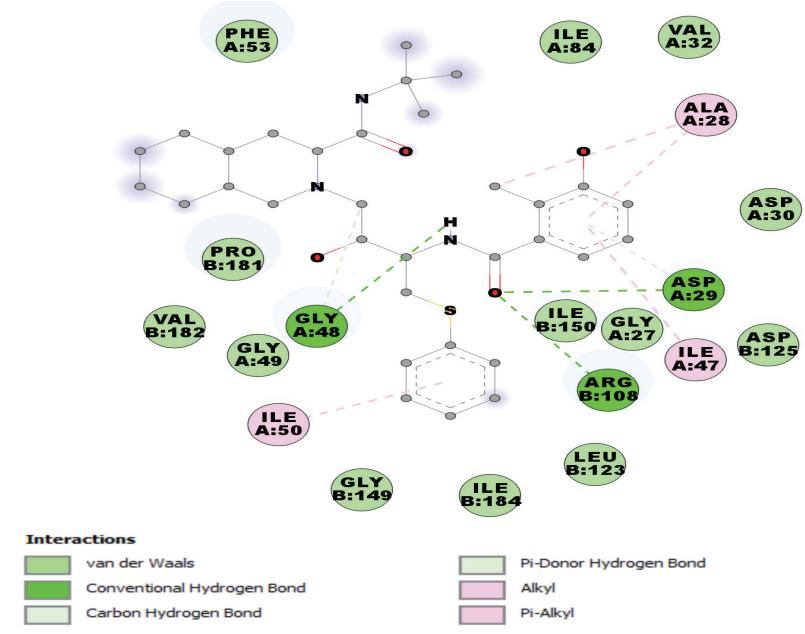

Figure 3. Docking position of amprenavir (A) and nelfinavir (B) on HIV-1 protease.

to inhibit HIV-1 protease. This drug only works on one area of the amino acid binding site, Asp-A: 25, whereas in this study, the ligand (5.beta.) pregnane-3, 20.beta.-diol, 14.alpha., 18.alpha .[4-methyl-3-oxo- (1-oxa-4-azabutane -1,4-diyl)],diacetate works in two areas of amino acid binding site. The more the bonds that form at the binding site area between the ligand and the receptor, the molecule will be more stable, and the energy will be more negative so that the potential activity of the ligand will be stronger (Manna et al., 2017; Nitami and Febriansah, 2019).

Mapanawang and Elim (2019) found that there were 15 active compounds present in this Pangi plant. Four of these compounds have the highest percentage levels and are thought to have an activity to inhibit the performance of HIV (Table 3 ).

The results of the binding affinity of the four compounds are not better than amprenavir, which has a binding affinity of $-12.8 \mathrm{kcal} / \mathrm{mol}$. However, squalene has a slightly higher affinity binding value than nelfinavir which has a binding affinity of -10.1 $\mathrm{kcal} / \mathrm{mol}$. The results of this in silico analysis also are shown in Mapanawang and Elim's (2019) research, in which some compounds in the Pangi leaves are thought to be able to inhibit the performance of HIV-1, especially in the HIV-1 protease enzyme. They proved this prediction through in vitro studies.

The compound (5.beta.) pregnane-3,20.beta.-diol, 14.alpha.,18.alpha.-[4-methyl-3-oxo-(1-oxa-4-azabutane-1,4diyl)]-diacetate was reported in Datura stramonium (Altameme et al., 2015) and Melissa officinalis (Fierascu et al., 2017). Plant D. stramonium was also reported to have an antiviral potential (Ivanov and Nikalov, 1988). Ethyl cholate and bis(3,5,5-trimethylhexyl) phthalate were reported to have potential antiviral activity against SARS-CoV-2 in an in silico study (Tallei et al., 2020).

To determine that a compound can be accepted as a lead compound, Lipinski's Ro5 can be used to evaluate the druglikeness of a chemical compound. We have the following criteria: (1) less than five hydrogen-bond donors, (2) less than ten hydrogen- 
A
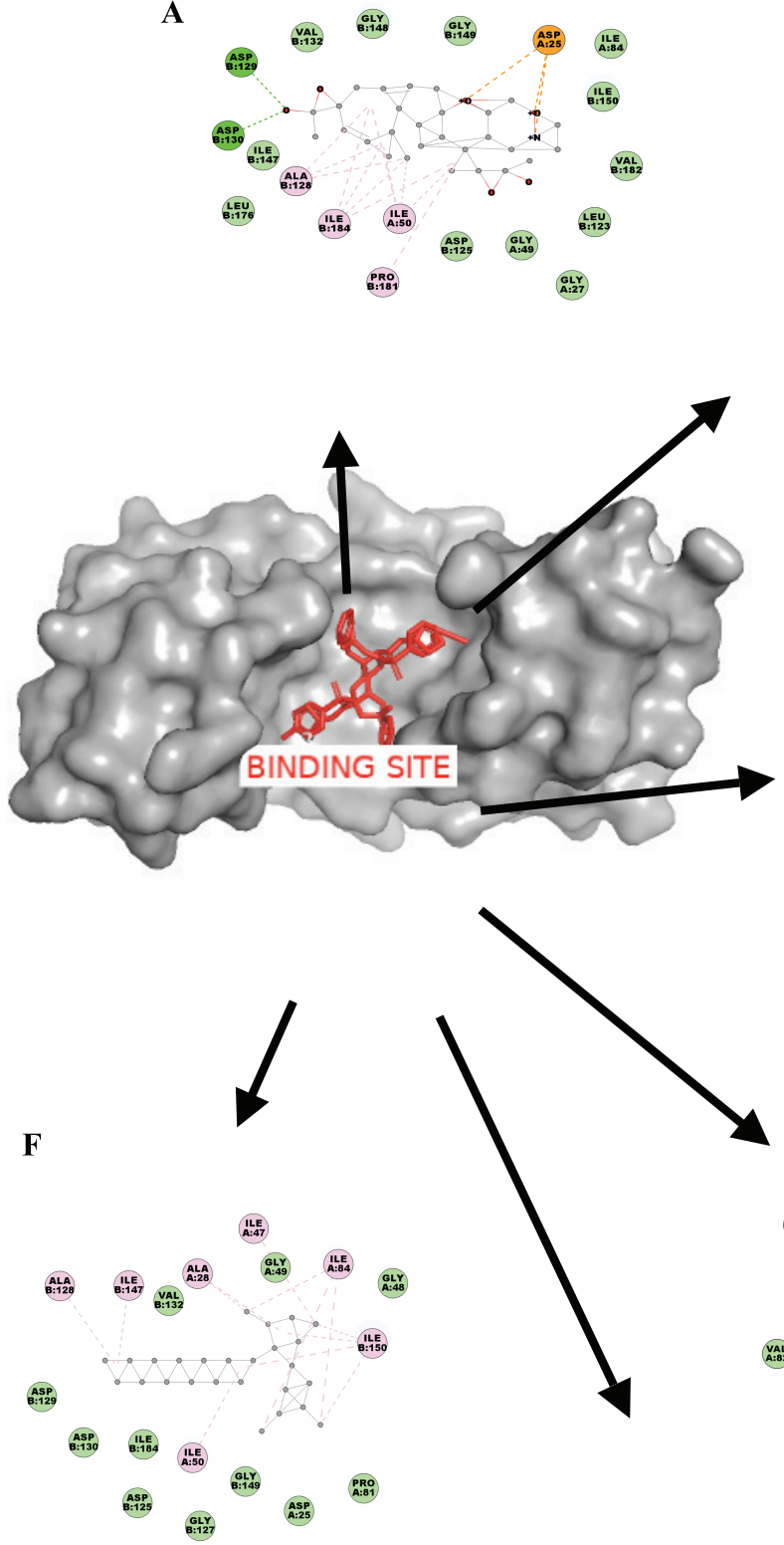

E
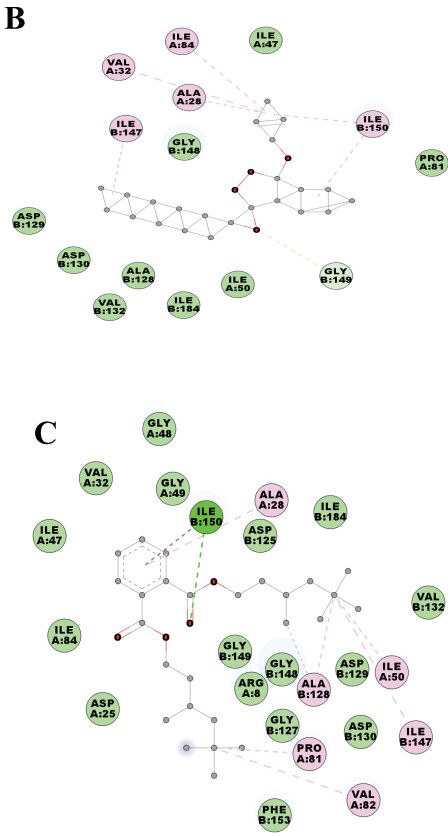
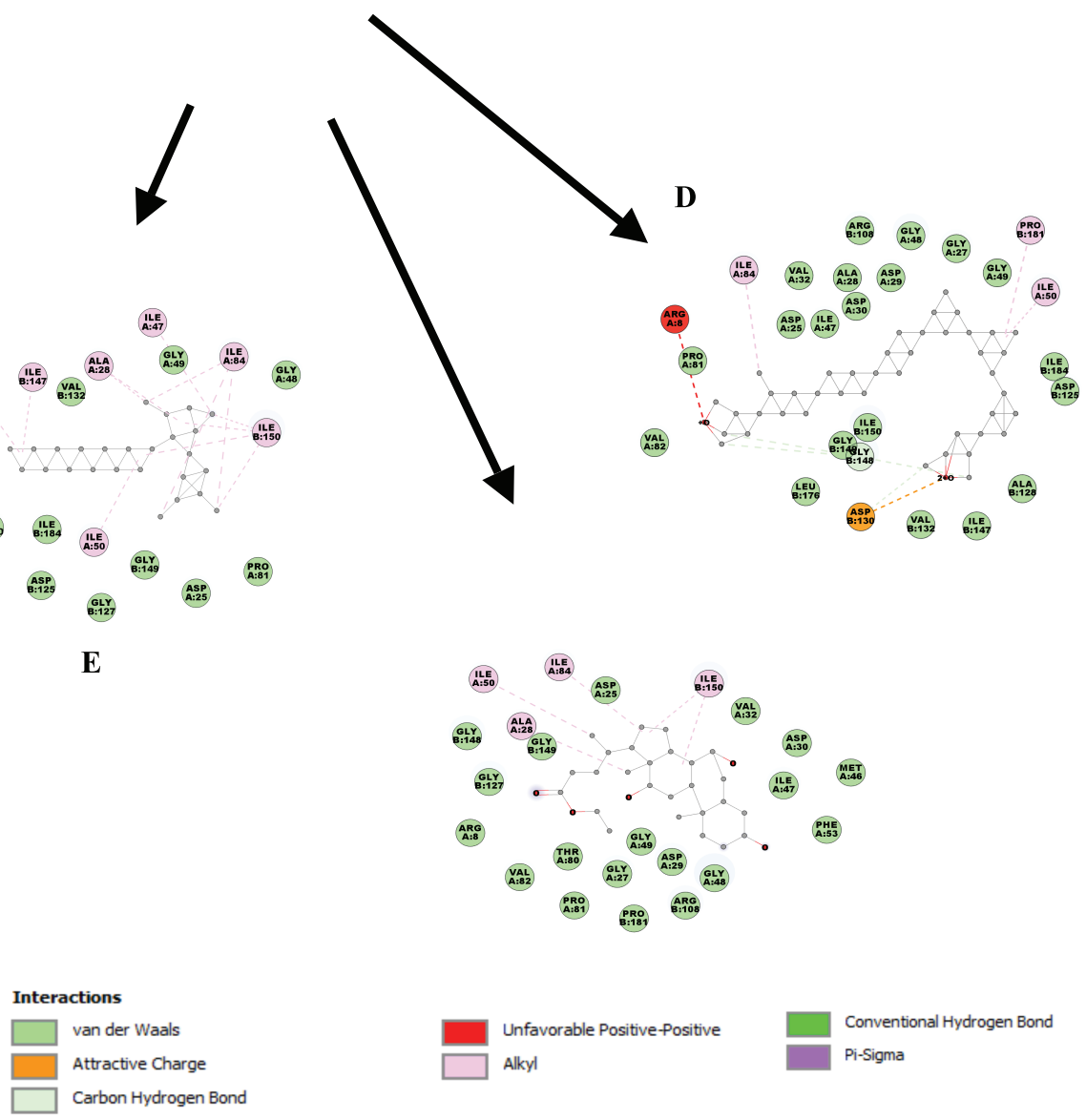

Figure 4. Docking position of (5.beta.) pregnane-3,20.beta.-diol, 14.alpha.,1 8.alpha.-[4-methyl-3-oxo-(1-oxa-4azabutane-1,4-diyl)]-diacetate (A), phthalic acid, butyl undecyl ester (B), bis(3,5,5-trimethylhexyl) phthalate (C), psi.,.psi.carotene, 1,1',2,2'-tetrahydro-1,1'-dimethoxy (D), ethyl cholate (E) dan octadecane, 3-ethyl-5-(2-ethylbutyl) (F) on HIV-1 protease protein. 
Table 3. The binding affinity of the compounds found in by Mapanawang and Elim (2019) and the percentage of their contents.

\begin{tabular}{clcc}
\hline Pubchem ID & Ligand properties & Binding affinity with 3NU3 & Percentage \\
\hline 5281 & Octadecanoic acid & -8.5 & $24.6 \%$ \\
6380722 & Squalene & -11.0 & $21.22 \%$ \\
985 & Hexadecanoic acid & -7.2 & $15.08 \%$ \\
5280435 & Phytol & -8.0 & $10.33 \%$ \\
\hline
\end{tabular}

bond acceptors, (3) molecular mass less than 500 Dalton, and (4) $\log$ P not greater than five (Shaji, 2018). Therefore, each docking compound was checked whether it met Lipinski's Ro5. This rule is used to determine whether certain chemical compounds have chemical and physical properties to be used as active drugs that can be taken orally in humans and evaluate the drug-likeness (Lipinski, 2004). Table 2 shows that 53 ligands have very low and low bioavailability because they only have at most one violation. Overall, the compound showed good compatibility as they satisfied Lipinski's Ro5. Therefore, these compounds might exhibit orally active drug-likeness. It means how a compound easily binds to receptor and how good its permeability across the cell membrane (Singh et al., 2013).

\section{CONCLUSION}

The existence of bioactive compounds shows the effective use of plant components by conventional experts for different circumstances. To sum up, the phytochemicals obtained from the leaf of $P$. edule exerted potential activity against HIV protease, of which (5.beta.) pregnane-3,20.beta.-diol, 14.alpha.,18.alpha.-[4methyl-3-oxo-(1-oxa-4-azabutane-1,4-diyl)]-diacetate., phthalic acid, butyl undecyl ester, bis(3,5,5-trimethylhexyl) phthalate, .psi.,.psi.-Carotene, 1,1',2,2'-tetrahydro-1,1'-dimethoxy-, ethyl cholate, octadecane, 3-ethyl-5-(2-ethylbutyl)- have possessed significant activity against HIV protease. The proposed in silico studies hence suggest that the $P$. edule extract could serve as an HIV-1 PI. Further experimental analysis might be needed to justify the activity of the phytochemicals at the molecular level. In addition, many more such bioactive ingredients from medicinal plants existing in the rich Indonesian biodiversity need to be further explored. This study could provide the basis for alternative therapeutics against the invading biological pathogens, including HIV.

\section{AUTHOR CONTRIBUTIONS}

All authors made substantial contributions to conception and design, acquisition of data, or analysis and interpretation of data; took part in drafting the article or revising it critically for important intellectual content; agreed to submit to the current journal; gave final approval of the version to be published; and agree to be accountable for all aspects of the work.

\section{FUNDING}

There is no funding to report.

\section{CONFLICTS OF INTEREST}

The authors report no conflicts of interest in this work.

\section{ETHICAL APPROVAL}

This study does not involve the use of animals or human subjects.

\section{REFERENCES}

Adamson CS. Protease-mediated maturation of HIV: inhibitors of protease and the maturation process. Mol Biol Int, 2012; 2012:1-13.

Al-Fifi Z, Saleh NA, Elhaes H, Ibrahim M. On the molecular modeling analyses of novel HIV-1 protease inhibitors based on modified chitosan dimer. Int J Spectrosc, 2015; 2015:1-9.

Altameme H, Muhanned K, Hammed I. Analysis of alkaloid phytochemical compounds in the ethanolic extract of Datura stramonium and evaluation of antimicrobial activity. Afr J Biotechnol, 2015; 14(9): $1668-74$.

Arts EJ, Hazuda DJ. HIV-1 antiretroviral drug therapy. Cold Spring Harb Perspect Med, 2012; 2(4):a007161.

Arwansyah, Ambarsari L, Sumaryada T. Simulasi docking senyawa kurkumin dan analognya sebagai inhibitor reseptor androgen pada kanker prostat. Curr Biochem, 2014; 1(1):11-9.

Badley AD. In vitro and in vivo effects of HIV protease inhibitors on apoptosis. Cell Death Differ, 2005; 12:924-31.

Barding GA, Béni S, Fukao T, Bailey-Serres J, Larive CK. Comparison of GC-MS and NMR for metabolite profiling of rice subjected to submergence stress. J Proteome Res, 2013; 12(2):898-909.

Bhatti AB, Usman M, Kandi V. Current scenario of HIV/AIDS, treatment options, and major challenges with compliance to antiretroviral therapy. Cureus, 2016; 8(3):1-12.

Brik A, Wong CH. HIV-1 Protease: mechanism and drug discovery. Org Biomol Chem, 2003; 1:5-14.

Calland N, Dubuisson J, Rouillé Y, Séron K. Hepatitis C Virus and natural compounds: a new antiviral approach? Viruses, 2012; 4:2197-217.

Chella Perumal P, Sowmya S, Pratibha P, Vidya B, Anusooriya P, Starlin T, Vasanth R, Jeya Sundra Sharmila D, Gopalakrishnan VK. Identification of novel PPAR $\gamma$ agonist from GC-MS analysis of ethanolic extract of Cayratia trifolia (L.): a computational molecular simulation studies. J Appl Pharm Sci, 2014; 4(9):6-11.

Estevam EC, Griffin S, Nasim MJ, Zieliñski D, Aszyk J, Osowicka M, Dawidowska N, Idroes R, Bartoszek A, Jacob C. Inspired by nature: the use of plant-derived substrate/enzyme combinations to generate antimicrobial activity in Situ. Nat Prod Commun, 2015; 10(10):1733-8.

Eurtivong C, Choowongkomon K, Ploypradith P, Ruchirawat S. Molecular docking study of lamellarin analogues and identification of potential inhibitors of HIV-1 integrase strand transfer complex by virtual screening. Heliyon, 2019; 5(11):4-11.

Fierascu I, Georgiev MI, Ortan A, Fierascu RC, Avramescu SM, Ionescu D, Sutan A, Brinzan A, Ditu LM. Phyto-mediated metallic nano-architectures via Melissa officinalis L.: synthesis, characterization and biological properties. Sci Rep, 2017; 7(1):12428.

Ghosh AK, Osswald HL, Prato G. Recent progress in the development of HIV-1 protease inhibitors for the treatment of HIV/AIDS. J Med Chem, 2016; 59(11):5172-208.

Głowacki ED, Irimia-Vladu $\mathrm{M}$, Bauer $\mathrm{S}$, Sariciftci NS. Hydrogen-bonds in molecular solids-from biological systems to organic electronics. J Mater Chem B, 2013; 1(31):3742-53.

Hu QF, Zhou B, Huang JM, Gao XM, Shu LD, Yang GY, Che CT. Antiviral phenolic compounds from arundina gramnifolia. J Nat Prod, 2013; 76(2):292-6.

Hughes PJ, Cretton-Scott E, Teague A, Wensel TM. Protease inhibitors for patients with HIV-1 infection a comparative overview. P T, 2011; 36(6):332-45.

Hussain SZ, Maqbool K. GC-MS: principle, technique and its application in food science. Int J Curr Sci, 2014; 13:116-26.

Ivanov I, Nikalov S. Tropane alkaloids in the pharmacognosy medicinal. Fizkuttura, Sofia, Bulgaria, 1988.

Kasim A, David W. Characteristic of Pangium edule reinw as food preservative from different geographical sites. Asia Pasific J Sustain Agric Food Energy, 2013; 1(1):6-9.

Ladokun OA, Abiola A, Okikiola D, Ayodeji F. GC-MS and molecular docking studies of hunteria umbellata methanolic extract as a potent anti-diabetic. Inform Med Unlocked, 2018; 13:1-8.

Lins L, Brasseur R. The hydrophobic effect in protein folding. FASEB J, 1995; 9(7):535-40. 
Lipinski CA. Lead- and drug-like compounds: the rule-of-five revolution. Drug Discov Today Technol, 2004; 1(4):337-41.

Maartens G, Celum C, Lewin SR. HIV infection: epidemiology, pathogenesis, treatment, and prevention. Lancet, 2014; 384(9939):258-71.

Manikrao A, Mahajan N, Jawarkar R, Khatale N, Kedar C, Thombare S. Docking analysis of darunavir as HIV protease inhibitors. J Comput Methods Mol Des Sch Res Libr, 2012; 2(1):39-43.

Manna A, Laksitorini MD, Hudiyanti D, Siahaan P. Molecular docking of interaction between E-cadherin protein and conformational structure of cyclic peptide ADTC3 (Ac-CADTPC-NH2) simulated on 20 ns. J Kim Sains Apl, 2017; 20(1):30-6.

Mapanawang AL, Elim HI. Pangi leaf (Pangium edule reinw) herbal medicine: a marvelous candidate for the prominent HIV herbal medicine. Sci Nat, 2019; 2(2):097-104.

Marchetti G, Tincati C, Silvestri G. Microbial translocation in the pathogenesis of HIV infection and AIDS. Clin Microbiol Rev, 2013; 26(1):2-18.

Membalik V, George YW, Rahman A, Asman A. Antifungal activities of Pangium edule reinhw seed extracts inhibts the growth of Aspergillus flavus, producer of aflatoxinx, through the in-vitro test. Int J Pharm Sci Res, 2018; 10(6):2718-22.

Moir S, Chun T-W, Fauci AS. Pathogenic mechanisms of HIV disease. Annu Rev Pathol Mech Dis, 2011; 6:223-48.

Morris G, Huey R, Lindstrom W, Sanner MF, Belew RiK, Goodsell DS, Olson AJ. AutoDock4 and AutoDockTools4: automated docking with selective receptor flexibility. J Comput Chem, 2009; 30(16):2785-91.

Naif HM. Pathogenesis of HIV infection. Infect Dis Rep, 2013; 5(Suppl.1):26-30.

Namthabad S, Mamidala E. Molecular docking of HIV-1 protease using alkaloids from tinospora cordifolia. Int J Res Appl, 2014; $1(1): 12-6$

Ningsih DS, Idroes R, Bachtiar BM, Khairan. The potential of five therapeutic medicinal herbs for dental treatment : a review. IOP Conf Ser: Mater Sci Eng, 2019; 523:012009.

Nitami SF, Febriansah R. Penambatan molekular senyawa tangeretin dan kampferol pada protein antiapoptosis Bcl-xL: studi in silico. Acta Pharm Indones, 2019; 7(2):42-50.

Nuraskin C, Marlina, Idroes R, Soraya C, Djufri. Identification of secondary metabolite of laban leaf extract (Vitex pinnata 1) from geothermal areas and non-geothermal of agam mountains in Aceh Besar, Aceh Province, Indonesia. Rasayan J Chem, 2020; 13(1):18-23.

Nuraskin CA, Marlina, Idroes R, Soraya C, Djufri. Activities inhibition methanol extract laban leaf (Vitex pinnata) on growth of bacteria S. mutans ATCC31987. IOP Conf Ser: Mater Sci Eng, 2019; 523:012008.

O'Boyle NM, Banck M, James CA, Morley C, Vandermeersch T, Hutchison GR. Open babel: an open chemical toolbox. J Cheminform, 2011; 3(33):1-14

Patick AK, Potts KE. Protease inhibitors as antiviral agents. Clin Microbiol Rev, 1998; 11(4):614-27.

Perez MAS, Fernandes PA, Ramos MJ. Drug design: new inhibitors for HIV-1 protease based on nelfinavir as lead. J Mol Graph Model, 2007; 26(3):634-42

Pratiwi SUT, Lagendijk EL, de Weert S, Idroes R, Hertiani T, Van den Hondel C. Effect of cinnamomum burmannii Nees ex B1. and massoia aromatica becc. Essential oils on planktonic growth and biofilm formation of pseudomonas aeruginosa and staphylococcus aureus in vitro. Int J Appl Res Natl Prod, 2015; 8(2):1-13.

Rahmad R, Earlia N, Nabila C, Inayati I, Amin M, Prakoeswa CRS, Khairan K, Idroes R. Antibacterial cream formulation of ethanolic pliek $\mathrm{U}$ extracts and ethanolic residue hexane pliek U extracts against Staphylococcus aureus. IOP Conf Ser: Mater Sci Eng, 2019; 523:012011.

Rakib A, Paul A, Chy MNU, Sami SA, Baral SK, Majumder M, Tareq AM, Amin MN, Shahriar A, Uddin MZ, Dutta M, Tallei TE, Emran TB, Simal-Gandara J. Biochemical and computational approach of selected phytocompounds from Tinospora crispa in the management of COVID-19. Molecules, 2020; 25(17):E3936.
Razzaghi-Asl N, Sepehri S, Ebadi A, Miri R, Shahabipoura S Effect of biomolecular conformation on docking simulation: a case study on a potent HIV-1 protease inhibitor. Iran J Pharm Res, 2015; 14(3):785-802.

Sakulpanich A, Gritsanapan W. Determination of anthraquinone glycoside content in Cassia fistula leaf extracts for alternative source of laxative drug. Int J Biomed Pharm Sci. 2009;3(1):42-5.

Sardi JCO, Scorzoni L, Bernardi T, Fusco-Almeida AM, Mendes Giannini MJS. Candida species: current epidemiology, pathogenicity, biofilm formation, natural antifungal products and new therapeutic options. J Med Microbiol, 2013; 62(Pt 1):1-31.

Shah TR, Misra A. Proteomics. In: Misra A (ed.). Challenges in delivery of therapeutic genomics and proteomics, 1st edition, Elsevier, Amsterdam, Netherlands, 2011.

Shaji D. Molecular docking studies of human MCT8 protein with soy isoflavones in allan-herndon-dudley syndrome (AHDS). J Pharm Anal, 2018; 8(5):318-23.

Sillapachaiyaporn C, Chuchawankul S. HIV-1 Protease and reverse transcriptase inhibition by tiger milk mushroom (Lignosus rhinocerus) sclerotium extracts: in vitro and in silico studies. J Tradit Complement Med, 2019; 10(4):4-12.

Simon V, Ho DD, Abdool Karim Q. HIV/AIDS epidemiology, pathogenesis, prevention, and treatment. Lancet, 2006; 368(9534):489-504

Singh S, Gupta AK, Verma A. Molecular properties and bioactivity score of the aloe vera antioxidant compounds - in order to lead fnding. Res J Pharm Biol Chem Sci, 2013; 4(2):876-81.

Tallei TE, Linelejan YT, Umboh SD, Adam AA, Muslem, Idroes R. Endophytic bacteria isolated from the leaf of Langusei (Ficus minahassae Tesym. \& De Vr.) and their antibacterial activities. IOP Conf Ser: Mater Sci Eng, 2019b; 796:012047

Tallei TE, Pelealu JJ, Pollo HN, Pollo GAV, Adam AA, Effendi Y, Karuniawan A, Rahimah A, Idroes R. Ethnobotanical dataset on local edible fruits in North Sulawesi, Indonesia. Data Brief, 2019a; 27:104681.

Tallei TE, Tumilaar SG, Niode NJ, Fatimawali F, Kepel BJ, Idroes R, Effendi Y, Sakib SA, Emran TB. Potential of plant bioactive compounds as SARS-COV-2 main protease $\left(\mathrm{M}^{\mathrm{Pro}}\right)$ and spike (S) glycoprotein inhibitors: A molecular docking study. Scientifica, 2020; Article ID 6307457 (In press).

Tian W, Chen C, Lei X, Zhao J, Liang J. CASTp 3.0: computed atlas of surface topography of proteins. Nucleic Acid Res. 2018; 46(21):W363-7.

Trott O, Olson AJ. AutoDock vina: improving the speed and accuracy of docking with a new scoring function, efficient optimization, and multithreading. J Comput Chem, 2009; 31(2):455-61.

Vijayan KV, Karthigeyan KP, Tripathi SP, Hanna LE Pathophysiology of CD4+ T-Cell depletion in HIV-1 and HIV-2 infections. Front Immunol, 2017; 8:1-8

World Health Organization. (2020). Available via https://apps. who.int/gho/data/view.main.22100WHO?lang=en. (Accessed: 14 July 2020)

Zhang S, Kaplan AH, Tropsha A. HIV-1 Protease function and structure studies with the simplicial neighborhood analysis of protein packing method. Proteins Struct Funct Genet, 2008; 73(3):742-53.

Zubair MS, Maulana S, Mukaddas A. Penambatan molekuler dan simulasi dinamika molekuler senyawa dari genus Nigella terhadap penghambatan aktivitas enzim protease HIV-1. J Farm Galen, 2020; $6(1): 132-40$.

\section{How to cite this article:}

Tumilaar SG, Fatimawali F, Niode NJ, Effendi Y, Idroes R, Adam AA, Rakib A, Emran TB, Tallei TE. The potential of leaf extract of Pangium edule Reinw as HIV-1 protease inhibitor: A computational biology approach. J Appl Pharm Sci, 2021; 11(01):101-110. 